Original article

\title{
Prevalence and pattern of multimorbidity among adults in a primary care rural setting
}

\author{
Saritha Susan Vargese*, Elsheba Mathew, Vinny Johny, Nisha Kurian, Gayathri A. V, \\ Aarya Serin Raju \\ Department of Community Medicine, Pushpagiri Institute of Medical Sciences and Research, Centre, Tiruvalla, Kerala, India
}

\section{A R T I C L E I N F O}

\section{Keywords:}

Multimorbidity

Primary care

Rural area

Public health

\begin{abstract}
A B S T R A C T
Background: Multimorbidity has substantial impact on the health of the individual in terms of safety, quality of life and functional ability, but little is known about it from rural areas in developing countries. Hence the present study attempted to determine the prevalence and gender difference in multimorbidity from a rural area.

Methods: A register based cross sectional study was done by retrieving data from the family health register of the rural health centre. Data on age, gender and all the morbidities, were collected. The most prevalent morbidities were presented as frequency and percentages, prevalence of multimorbidity were presented as dyads and triads. Multiple Logistic regression was done to find the age adjusted risk of gender on multimorbidity.

Results: The prevalence of multimorbidity was $16.2 \%$ (13.05-19.35). The most prevalent morbidities were hypertension, diabetes, dyslipidaemia, visual impairment and thyroid in both males and females and most common dyad was hypertension and diabetes.

Conclusion: In the context of lack of studies from this area, the findings of the study may help the health care providers to plan interventions. Further research has to be done to identify the risk factors of multimorbidity.
\end{abstract}

\section{Introduction}

Co-occurrence of two or more chronic conditions, commonly referred to as 'multimorbidity' is increasingly being recognised among individuals globally ${ }^{1}$ improvement in life expectancy and living conditions. With population ageing, multimorbidity has become progressively more common ${ }^{2,3}$ in developed ${ }^{4}$ as well as developing countries. ${ }^{2,5}$ The higher burden has led to greater concern over the related decline in quality of life and functional ability, high mortality and medical expenditure. ${ }^{6}$

Furthermore, morbidity and mortality rates seem to be higher in older adults with lower education and socioeconomic status. ${ }^{7,8}$

A systematic review on multimorbidity in primary care demonstrated a high prevalence ranging from $30 \%$ in all adults to $60 \%$ among those aged 65-74 years, however majority were western studies. ${ }^{9}$ Recently high levels of multimorbidity has been shown in low- and middle income countries as well. ${ }^{10} \mathrm{~A}$ multistate study including rural and urban areas reported a prevalence of $37.3 \%$ among adults over 60 years of age. Initially thought to be a geriatric phenomenon, recent studies have revealed that younger adults also exhibit a considerable prevalence of multimorbidity. ${ }^{11,12}$
People with multimorbidity are more prone for safety issues Poor health, advanced age, susceptible to infections cognitive impairment, demanding self-management regimens and competing priorities, inadequate health literacy; polypharmacy, complex treatment regimens, greater chance of failures in care delivery requiring frequent and complex interactions complex patient needs which need clear communication and patient-centred care. ${ }^{13-15}$

Awareness about primary care and self-care are essential for the overall health of these patients. It is a challenge to health delivery system, health professionals and managers. Identification and effective management are required to control this rising challenge. In this context, the present study aimed at determining the prevalence and pattern of multimorbidity and associated sociodemographic factors in the adult population in a rural area in South Kerala. The findings may provide primary care clinicians and policy makers with better epidemiological understanding of multimorbidity for planning appropriate care.

\section{Methods}

A register based cross sectional study was done in the field practice area of rural health training centre(RHTC) of Pushpagiri Institute of

\footnotetext{
* Corresponding author.

E-mail address: dr.sarithasusan@yahoo.in (S.S. Vargese).
} 
Table 1

Basic characteristics of the study sample $(\mathrm{N}=525)$.

\begin{tabular}{ll}
\hline Characteristics of the study population & No. (\%) \\
\hline Age in years & \\
$18-29$ & $106(20.0)$ \\
$30-39$ & $96(18.3)$ \\
$40-49$ & $90(17.1)$ \\
$50-59$ & $86(16.4)$ \\
$60-69$ & $86(16.4)$ \\
$>70$ & $62(11.8)$ \\
\hline Gender & \\
Male & $246(46.9)$ \\
Female & $279(53.1)$ \\
\hline Education & \\
Illiterate & $13(02.5)$ \\
Primary \& middle school & $87(16.6)$ \\
High school \&higher secondary & $272(51.8)$ \\
Graduate \& above & $153(29.1)$ \\
\hline Occupation & \\
Unemployed & $242(46.1)$ \\
Unskilled, semi-skilled, skilled & $255(48.3)$ \\
Semi-professional, Professional & $28(05.3)$ \\
\hline
\end{tabular}

Table 2

Gender specific morbidity pattern in the study sample.

\begin{tabular}{llll}
\hline Morbidity & Males: No (\%) & Females: No (\%) & p value $^{\mathrm{a}}$ \\
\hline 0 & $152(61.8)$ & $177(63.4)$ & \\
1 & $58(23.6)$ & $53(19)$ & 0.33 \\
2 & $29(11.8)$ & $32(11.5)$ & \\
3 & $6(2.4)$ & $13(4.7)$ & \\
4 & $1(1.1)$ & $4(1.4)$ & \\
Total & $246(100)$ & $279(100)$ & \\
\hline
\end{tabular}

${ }^{\text {a }}$ Chi square test.

Medical Sciences and Research Centre, Kerala for a period of two months. The ward is mostly water logged area with paddy fields, with independent houses. The other health facilities available are government primary and community health centres and a few private clinics with the nearest referral centre being $15 \mathrm{~km}$ away. The family register maintained at the RHTC has information on socio-demographic characteristics and self-reported morbidities of all the residents in the field practice area updated in 2017.Data was extracted from the registers after Institutional ethics committee approval was obtained. For the purpose of this study, one ward was selected by simple random sampling, data on twelve disease conditions included in the assessment of multimorbidity, and updated data on age, gender, occupation and education were extracted. Multimorbidity was defined as having 2 or more chronic conditions. The diseases considered were diabetes, hypertension, dyslipidaemia, cardiovascular diseases, stroke, cancer, dementia, psychiatric disorders, cataract, renal diseases, arthritis, peptic ulcer. The most common conditions, and frequency of dyads, triads and combinations of diseases were calculated. The data are presented as mean (standard deviation) and percentages. Prevalence of multimorbidity was calculated across socio-demographic variables. Linear by linear trend test was done for multimorbidity across the age groups. A $t$ test was done to find the difference in number of morbidities in men and women. Binary logistic regression was done to identify the sociodemographic factors associated with multimorbidity. Statistical analysis was done using SPSS version 25 . A confidence interval of $95 \%$ was calculated and level of significance was set at $\mathrm{p}<0.05$.

\section{Results}

The study sample consisted of 525 adults whose basic sociodemographic characteristics are depicted in Table 1.

The mean (SD) age of the study sample was $47.36(18.35)$ years, and $46.9 \%$ were males. Mean (SD) age of males was $47.38(17.42)$ and females 47.35(19.16) years. Majority(70\%) had an education above high school while only $5.3 \%$ were engaged in semi-professional and professional jobs.

Multimorbidity was reported in $16.2 \%$ (13.05-19.35) of the study sample and $37.3 \%$ had at least one of the chronic conditions. There was significant difference $(\mathrm{p}=0.02)$ in the mean number of diseases in men $(2.11 \pm 0.46)$ and women $(2.24 \pm 0.72)$.

Table 2 shows the prevalence of dyads and triads in men and women. There was no significant difference in the pattern of morbidity between males and females.

As shown in Fig. 1, the most common morbidities were similar in men and women viz. diabetes $(p=0.41)$, hypertension $(p=0.08)$, dyslipidaemia $(\mathrm{p}=0.36)$. The other common morbidities were visual impairment, thyroid related, asthma and varicose veins which also did not show significant gender difference.

Table 3 describes the association between multimorbidity and sociodemographic variables. The prevalence of multimorbidity ranged from $1.2 \%$ in those aged $18-29$ years to $27.1 \%$ in those above 70 years. The prevalence of multimorbidity among older adults (above 60 years) was $61.2 \%$. The odds of having multimorbidity increased with age and this trend was significant $(\mathrm{p}<0.001)$. Out of those having multimorbidity, $57.6 \%$ were females and $55.3 \%$ were unemployed. Education and occupation were not found to be associated with multimorbidity. Age above 40 years was found to be a risk factor even after adjusting for gender, education and occupation.

Fig. 2 describes the proportion of adult males and females with multimorbidity in the different age groups.

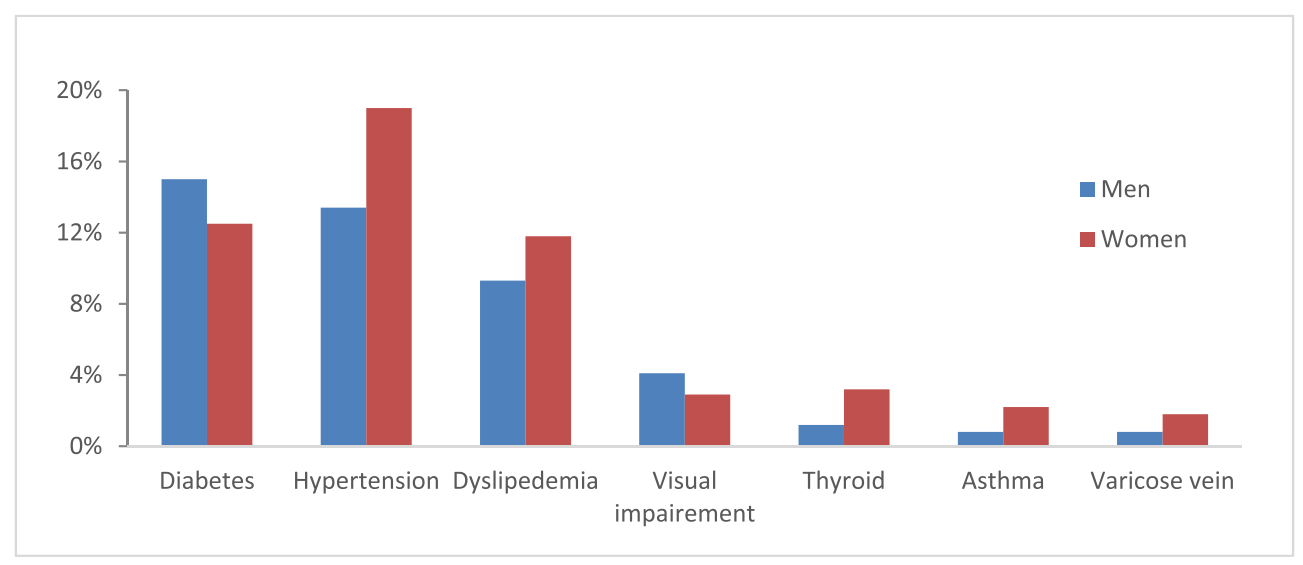

Fig. 1. Gender wise comparison of common diseases in the study sample. 
Table 3

Prevalence of Multimorbidity according to sociodemographic characteristics: Results from univariate and multivariate analyses.

\begin{tabular}{|c|c|c|c|c|c|}
\hline \multirow[t]{4}{*}{ Variable } & \multicolumn{2}{|c|}{ Multimorbidity } & \multirow[t]{4}{*}{ Crude Odds ratio( $95 \% \mathrm{CI})$} & \multirow[t]{4}{*}{ Adjusted Odds ratio(95\% CI) ${ }^{b}$} & \multirow[t]{4}{*}{$P$ value } \\
\hline & No & Yes & & & \\
\hline & $\mathrm{n}=440$ & $(\mathrm{n}=85)$ & & & \\
\hline & $\mathrm{n}(\%)$ & $\mathrm{n}(\%)$ & & & \\
\hline \multicolumn{6}{|l|}{ Age in years } \\
\hline $18-29$ & 104(99.0) & $1(1.2)$ & Reference & Reference & \\
\hline $30-39$ & $93(96.9)$ & $3(3.5)$ & $3.36(0.34-32.81)$ & $2.81(27-28.99)$ & 0.38 \\
\hline $40-49$ & $79(87.8)$ & $11(12.9)$ & $14.48(1.83-114.52)$ & $11.97(1.43-99.22)$ & $<0.05$ \\
\hline $50-59$ & $68(79.1)$ & $18(21.2)$ & 27.53(3.59-211.03) & $19.42(2.39-157.79)$ & $<0.01$ \\
\hline $60-69$ & $57(66.3)$ & $29(34.1)$ & 52.91(7.02-398.66) & $37.99(4.68-308.42)$ & $<0.01$ \\
\hline$>70$ & $39(62.9)$ & $23(37.1)$ & $61.33(8.01-469.65)$ & $42.56(5.15-352.42)$ & $<0.01$ \\
\hline \multicolumn{6}{|l|}{ Gender } \\
\hline Male & $210(85.4)$ & $36(42.4)$ & Reference & Reference & \\
\hline Female & $230(82.4)$ & $49(57.6)$ & $0.81(0.50-1.29)$ & $1.23(0.62-2.44)$ & 0.55 \\
\hline \multicolumn{6}{|l|}{ Education } \\
\hline Illiterate & $9(69.2)$ & $4(4.7)$ & Reference & Reference & \\
\hline Primary \& middle school & $63(72.4)$ & $24(28.2)$ & $0.86(0.24-3.05)$ & $0.91(0.24-3.47)$ & 0.88 \\
\hline High school \& higher secondary & $219(80.5)$ & $53(62.4)$ & $0.56(0.16-1.84)$ & $1.20(0.32-4.51)$ & 0.78 \\
\hline Graduate \& above & $149(97.4)$ & $4(4.7)$ & $0.06(0.01-0.28)$ & $0.18(0.03-1.12)$ & 0.06 \\
\hline \multicolumn{6}{|l|}{ Occupation } \\
\hline Unemployed & 195(80.6) & $47(55.3)$ & Reference & Reference & \\
\hline Unskilled, skilled, semiskilled & $172(57.6)$ & $36(42.4)$ & $0.68(0.42-1.09)$ & $0.90(0.44-1.85)$ & 0.77 \\
\hline Semi-professional/Professional & $73(88)$ & $2(2.4)$ & $0.32(0.07-1.39)$ & $4.23(.56-32.19)$ & 0.16 \\
\hline
\end{tabular}

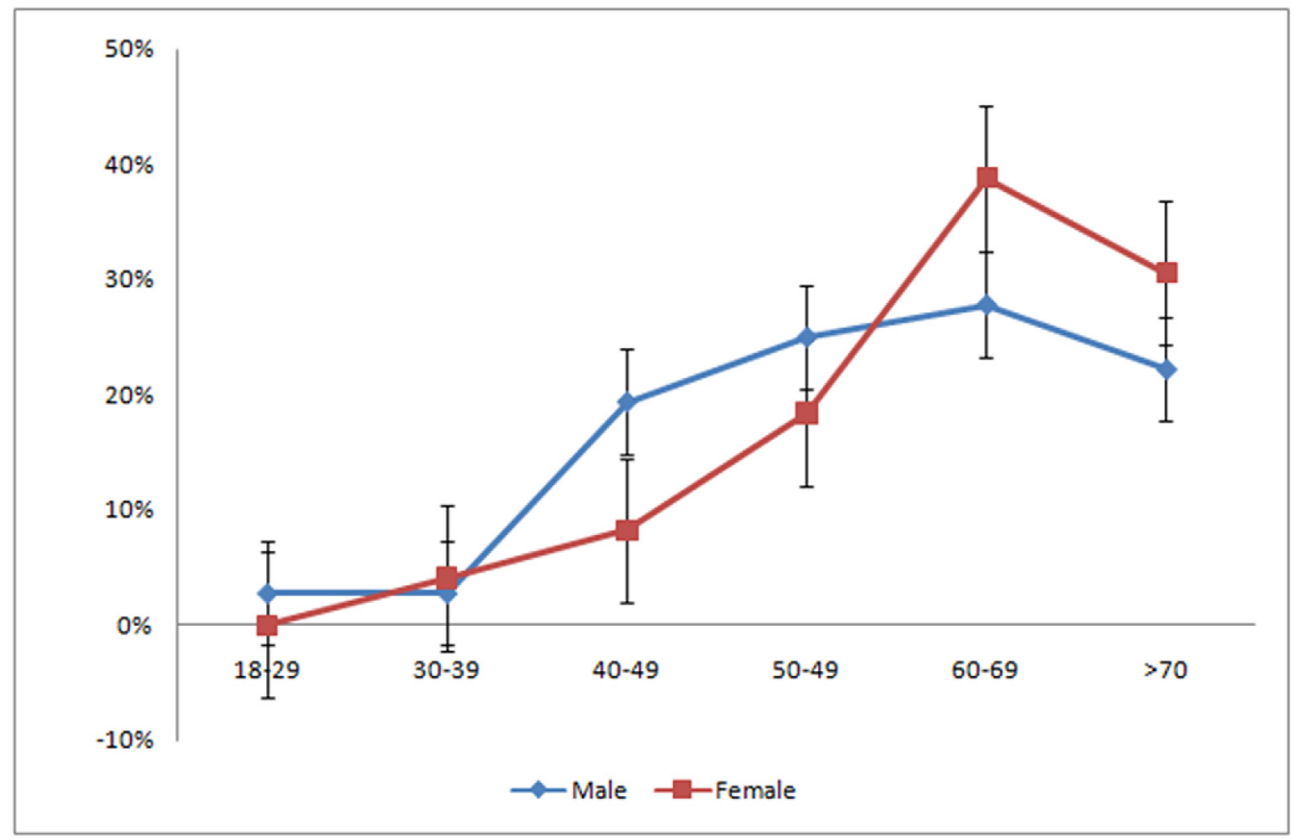

Fig. 2. Prevalence of multimorbidity in the study sample, by age and sex.

In males, prevalence of multimorbidity rises at a younger age, increasing rapidly across the middle age and then decreasing. In females, prevalence of multimorbidity gradually increases over the years and peaks at around 60 years to a higher level than that of males with similar decline in the next decade. The trend across the age groups was highly significant $(\mathrm{p}<0.0001)$ in both genders.

\section{Discussion}

The cross-sectional register based study investigated the prevalence and pattern of multimorbidity among 525 adults in a rural area of Kerala. The prevalence of multimorbidity was found to be $16.2 \%$ among adults; $61.2 \%$ among those above 60years.A systematic review from South Asia reported prevalence of multimorbidity from $4.5 \%$ to
$83 \%{ }^{16}{ }^{\text {The prevalence was } 57.2 \%}$ (95\% CI 56.6\%-58.7\%) in Brazil ${ }^{17}$; $23.2 \%(23.08-23.21)$ in Scotland ${ }^{18} ; 35.7 \%(34.8 \%-36.7 \%)$ in Indonesia $^{19} ; 28.3 \%$ in a northern state in India. ${ }^{20}$ The lower prevalence in the study may be because of the underutilization of health services, or socio cultural difference in agricultural community. A recent study from Odisha reported $44.4 \%$ multimorbidity in those above $70 \mathrm{yrs}$ when compared to $37.1 \%$ in the current study, however the former listed 22 health conditions the latter twelve. ${ }^{20}$ The mean number of diseases in men and women(men $2.11 \pm 0.46$; female $2.24 \pm 0.72 ; \mathrm{p}=0.021$ ) was higher when compared to studies from other parts of the world, $1.2 \pm 1.5$ per person in Brazil, $1.27 \pm 0.01$ in Indonesia.

The study confirms the higher multimorbidity in the older age groups. There was significant association between age and multimorbidity, odds of multimorbidity increased as the age increased. The 
risk doubled in a decade from 40 years onwards. The higher likelihood of multimorbidity among older adults was congruent with findings from other states of India and the Western world. ${ }^{18} \mathrm{~A}$ study from Indonesia among adults above $40 y$ ears reported $35.7 \%$ similar to the findings in our study (33.3\%). ${ }^{19}$

The most common diseases reported were diabetes, hypertension and dyslipidaemia which was very similar to those reported from other parts of India as well as developed countries. ${ }^{14,16,19,21}$

Multimorbidity did not show any difference in the two genders in the present study whereas other studies in Asian countries have reported significantly higher prevalence among women (41.5\% vs $29.5 \%$; $\mathrm{p}<0.001)^{19,22}$ and have also shown higher risk of multiple morbidities amongwomen. ${ }^{19}$

The clinical guidelines for treating as single diseases which is most widely practiced, may not be appropriate in individuals with multimorbidity. The study underscores the need for formulating protocols considering the complexity of presentation of multimorbidity, comprehensive screening, and management. The cross sectional design of the study limits the investigation of temporal association. The accuracy of self-reported diagnosis may be leading to under or over reporting, and the information from a single ward may not be generalisable.

\section{Conclusion}

In the present study prevalence of multimorbidity was $16.2 \%$ with no gender difference and more than a third had at least one chronic disease. Diabetes, hypertension and dyslipidaemia were the most prevalent conditions in both genders. Further studies are required to look at the incidence and outcomes to suitably modify health care delivery system, to accommodate for the complexity of multimorbidity.

\section{Funding}

This research did not receive any specific grant from funding agencies in the public, commercial, or not-for-profit sectors.

\section{Declaration of competing interest}

Nil.

\section{Acknowledgement}

We express our deep sense of gratitude to the Department of Community Medicine, Pushpagiri Institute of Medical Sciences, Tiruvalla, Kerala for all the support.

\section{References}

1. Garin N, Koyanagi A, Chatterji S, et al. Global multimorbidity patterns: a cross-sectional, population-based, multi-country study. J Gerontol A Biol Sci Med Sci. 2016;71:205-214. https://doi.org/10.1093/gerona/glv128 PMID: 26419978.
2. Khanam MA, Streatfield PK, Kabir ZN, et al. Prevalence and patterns of multimorbidity among elderly people in rural Bangladesh: a cross-sectional study. J Health Popul Nutr. 2011;29 406-14 WHO - Multimorbidity; Technical series on primary care- page 3

3. Marengoni A, Angleman S, Melis R, et al. Aging with multimorbidity: a systematic review of the literature. Ageing Res Rev. 2011;10:430-439.

4. Salisbury C, Johnson L, Purdy S, et al. Epidemiology and impact of multimorbidity in primary care: a retrospective cohort study. Br J Gen Pract. 2011;61:e12-21.

5. Arokiasamy P, Uttamacharya P, Jain K. Multi-morbidity, Functional Limitations, and Self-Rated Health Among Older Adults in India: Cross-Sectional Analysis of LASI Pilot Survey, 2010. SAGE Open; 2015.

6. WHO - Multimorbidity; Technical Series on Primary Care- Page 3.

7. McMunn A, Breeze E, Goodman A, Nazroo J, Oldfield Z. Social determinants of health in older age. Social Determinants of health.cEdited by: Marmot M. Wilkinson R. Oxford: University Press; 2006:267-296.

8. Kok R, Avendano M, Mackenbach JP. The association between socioeconomic status and changes in health in Europe. In: Börsch-Supan A, Brugiavini A, Jürges H, eds. Health, Ageing and Retirement in Europe (2004-2007): Starting the Longitudinal Dimension. Mannheim: Strauss; 2008:123-128.

9. France EF, Wyke S, Gunn JM, Mair FS, McLean G, Mercer SW. Multimorbidity in primary care: a systematic review of prospective cohort studies. Br J Gen Pract J R Coll Gen Pract. 2012;62:e297-307. https://doi.org/10.3399/bjgp12X636146 PMID: 22520918.

10. Wang HH, Wang JJ, Wong SY, et al. Epidemiology of multimorbidity in China and implications for the health care system: crosssectional survey among 162,464 community household residents in southern China. BMC Med. 2014;12(1) 188.

11. Prados-Torres A, Poblador-Plou B, Calderon-Larranaga A, et al. Multimorbidity patterns in primary care: interactions among chronic diseases using factor analysis. PLoS One. 2012;7:e32190.

12. Smith SM, Ferede A, O'Dowd T. Multimorbidity in younger deprived patients: an exploratory study of research and service implications in general practice. BMC Fam Pract. 2008;9. https://doi.org/10.1186/1471-2296-9-6 PMID: 18226249.

13. Phillips RL, Bartholomew LA, Dovey SM, Fryer GE, Miyoshi TJ, Green LA. Learning from malpractice claims about negligent, adverse events in primary care in the United States. Qual Saf Health Care. 2004;13(2):121-126.

14. Mini GK, Thankappan KR. Pattern, correlates and implications of non-communicable disease multimorbidity among older adults in selected Indian states: a cross-sectional study. BMJ Open. 2017;7(3) https://doi.org/10.1136/bmjopen-2016-013529.

15. Arokiasamy P, Uttamacharya U, Jain K, et al. The impact of multimorbidity on adult physical and mental health in low- and middle-income countries: what does the study on global ageing and adult health (SAGE) reveal? BMC Med. 2015;13. https://doi. org/10.1186/s12916-015-0402-8.

16. Pati S, Swain S, Hussain MA, et al. Prevalence and outcomes of multimorbidity in South Asia: a systematic review. BMJ Open. 2015;5(10) https://doi.org/10.1136/ bmjopen-2014-007235.

17. Araujo MEA, Silva MT, Galvao TF, Nunes BP, Pereira MG. Prevalence and patterns of multimorbidity in Amazon Region of Brazil and associated determinants: a crosssectional study. BMJ Open. 2018;8(11) https://doi.org/10.1136/bmjopen-2018023398.

18. Barnett K, Mercer SW, Norbury M, Watt G, Wyke S, Guthrie B. Epidemiology of multimorbidity and implications for health care, research, and medical education: a cross-sectional study. The Lancet. 2012;380(9836):37-43. https://doi.org/10.1016/ S0140-6736(12)60240-2.

19. Hussain MA, Huxley RR, Al Mamun A. Multimorbidity prevalence and pattern in Indonesian adults: an exploratory study using national survey data. BMJ Open. 2015;5(12) https://doi.org/10.1136/bmjopen-2015-009810.

20. Pati S, Swain S, Hussain MA, Kadam S, Salisbury C. Prevalence, correlates, and outcomes of multimorbidity among patients attending primary care in Odisha, India. Ann Fam Med. 2015;13(5):446-450. https://doi.org/10.1370/afm.1843.

21. Fortin M, Bravo G, Hudon C, Vanasse A, Lapointe L. Prevalence of multimorbidity among adults seen in family practice. Ann Fam Med. 2005;3(3):223-228. https://doi org $/ 10.1370 / \mathrm{afm} .272$

22. Pati S, Swain S, Metsemakers J, Knottnerus JA, van den Akker M. Pattern and severity of multimorbidity among patients attending primary care settings in Odisha, India. PLoS One. 2017;12(9) https://doi.org/10.1371/journal.pone.0183966. 